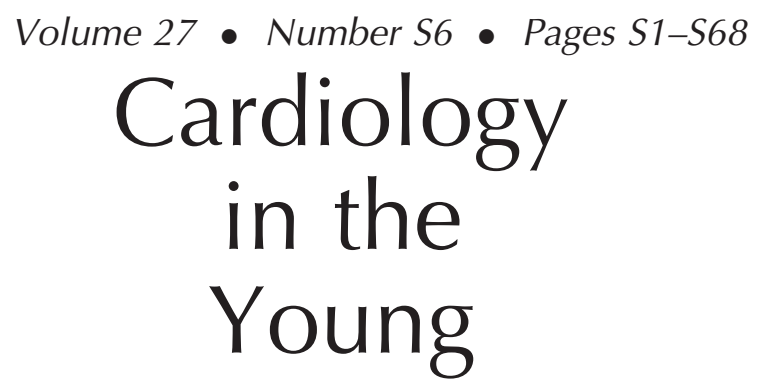

COPYRIGHT C 2017 CAMBRIDGE UNIVERSITY PRESS ISSN 1047-9511

\title{
Table of Contents
}

\section{Special Supplement of Cardiology in the Young}

Pediatric Cardiac Intensive Care Society statement: caring for children with critical cardiac disease across the globe

Katherine L. Brown, Dorothy M. Beke, David S. Cooper, Graeme MacLaren

The global burden of paediatric heart disease

Ndidiamaka L. Musa, Vibeke Hjortdal, Bistra Zheleva, Indah K. Murni, Shunji Sano, Steven Schwartz,

Sandra L. Staveski

Global perspective on training and staffing for paediatric cardiac critical care

Ronald A. Bronicki, Uri Pollack, Andrew C. Argent, R. Krishna Kumar, Maria Balestrini, Paola Cogo,

Bruna Cury Borim, Kumi De Costa, John Beca, Naoki Shimizu, Troy E. Dominguez

Perioperative infections in congenital heart disease

Indah K. Murni, Graeme MacLaren, Debra Morrow, Parvathi Iyer, Trevor Duke

Management of undernutrition and failure to thrive in children with congenital heart disease in low- and middle-income countries

Andrew C. Argent, Rakhi Balachandran, Balu Vaidyanathan, Amina Khan, R. Krishna Kumar

Management of late presentation congenital heart disease

Parvathi U. Iyer, Guillermo E. Moreno, Luiz Fernando Caneo, Tabira Faiz, Lara S. Shekerdemian,

Krishna S. Iyer

Inter-hospital transport of the child with critical cardiac disease

Padmanabhan Ramnarayan, Zafurallah Intikhab, Neil Spenceley, Ilias Iliopoulos, Alana Duff,

Johnny Millar

Medical missions for the provision of paediatric cardiac surgery in low- and middle-income countries

Frank J. Molloy, Nguyenvu Nguyen, Marisa Mize, Gavin Wright, Cecilia St. George-Hyslop, Maura O'Callaghan, Emma Scanlan, William M. Novick

Partnership models for the establishment of sustainable paediatric cardiac surgical and cardiac intensive care programmes in low- and middle-income countries

Patricia Bastero, Sandra L. Staveski, Bistra Zheleva, Emma Scanlan, Antonio G. Cabrera, Aric Araujo, Guillermo Reyes, Carlos M. Mery, Alexis Palacios-Macedo, Christian P. Brizard 
Cardiol Young (2017), 27 (Suppl. 6), S1-S68

(C) Cambridge University Press

ISSN 1047-9511

\section{Table of Contents continued}

International quality improvement initiatives

Patricia A. Hickey, Jean A. Connor, Kotturathu M. Cherian, Kathy Jenkins, Kaitlin Doherty, Haibo Zhang,

Michael Gaies, Sara Pasquali, Sarah Tabbutt, James D. St. Louis, George E. Sarris, Hiromi Kurosawa,

Richard A. Jonas, Nestor Sandoval, Christo I. Tchervenkov, Jeffery P. Jacobs, Giovanni Stellin, James K. Kirklin,

Rajnish Garg, David F. Vener

This journal issue has been printed on FSC-certified paper and cover board. FSC is an independent, non-governmental, not-for-profit organization established to promote the responsible management of the world's forests. Please see www.fsc.org for information

Cardiology in the Young (C) 2017 Cambridge University Press, ISSN 1047-9511 is published bi-monthly

Subscription information: Volume 27 (10 issues) will appear in 2017. Correspondence concerning subscriptions should be addressed to: Journals Customer Services, Cambridge University Press, UPH, Cambridge CB2 8BS, UK. Tel: +44 (0)1223 326070; Fax: +44 (0)1223 325150; E-mail enquiries: journals_subscriptions@ @ambridge.org; Web: www.cambridge.org; Cambridge Journals Online: www.journals.cambridge. org/cty. The subscription rate for 2017 Volume 27 (10 issues) is: Institutional electronic only rate $£ 1338$ or US $\$ 2274$. Cheques should be made payable to Cambridge University Press. Copyright: The submission of a manuscript implies the following: (a) that the work described has not been published before, except in the form of an abstract or as part of a published lecture, review, or thesis; (b) that it is not under consideration for publication elsewhere; (c) that all co-authors approve its publication; (d) that its publication is approved by the responsible authorities at the institute where the work has been carried out; (e) that when the manuscript is accepted for publication, the authors agree to the automatic transfer of the copyright to the publisher; (f) that the manuscript will not be published elsewhere in any language without the consent of the copyright holders, and $(\mathrm{g})$ that written permission of the copyright holder is obtained by the authors for material used from other copyrighted sources. All articles published in this journal are

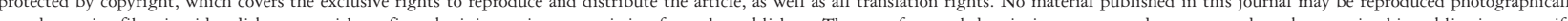
specifically identified, does not imply that these names are not protected by the relevant laws and regulations. While the advice and information in this journal are believed to be true and accurate at the date of its going to press, neither the authors, the editors, the publisher, nor any affiliated Society can accept any legal responsibility for any errors or omissions that may be made. The publisher nor any affiliated Society make no warranty, express or implied, with respect to the material contained herein. Cambridge University Press publishes advertisements in this journal while relying on the responsibility of the advertiser to comply with all legal requirements relating to the marketing and sale of products or services advertised. Cambridge University Press and the editors are not responsible for claims made in the advertisements published in the journal. The appearance of advertisements in Cambridge University Press publications does not constitute endorsement, implied or intended, of the product advertised or the claims made for it by the advertiser. Photocopies may not be made for personal or in-house use beyond the limitations stipulated under US Copyright Law. Advertisements: For advertisement rates and information on advertisement copy contact Cardiology in the Young, Advertising Dept, Cambridge University Press (Journals), UPH, Shaftesbury Road, Cambridge CB2 8BS, UK. Tel: + 44 (0)1223 $325083 ;$ Fax: + 44 (0)1223 325801; the Subscription Department. Send new address and postal code, and the address label from a current issue to Journals Customer Services, Cambridge University Press, FREEPOST CB27, UPH, Cambridge CB2 8BS, UK. Tel: +44 (0)1223 326070; Fax: +44 (0)1223 325150; E-mail enquiries: journals_subscriptions@cambridge.org; Web; www.cambridge.org; Cambridge Journals Online: www.journals.cambridge.org Printed by Bell \& Bain, Glasgow, UK. 


\section{Association for European Paediatric and Congenital Cardiology (AEPC)}

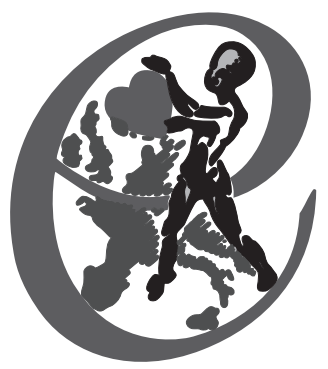

A EPC WAS FOUNDED IN LYON IN 1963 (as Association Européenne pour la Cardiologie Pédiatrique) and subsequently has created a network of specialists who are committed to the practice and advancement of Congenital Cardiology and closely related fields. Cardiology in the Young is the official journal of the AEPC. AEPC offers a free subscription of 'Cardiology in the Young' (CitY) as part of the annual membership fee. The membership also offers several other benefits.

The overall membership of the Association currently stands at 1300 paediatric cardiologists and other specialists working in the field of paediatric cardiology and its related disciplines. As far as we are aware, the AEPC is the largest democratically administered global association in the field of paediatric and congenital cardiology. Members of the AEPC originate from virtually all countries in Europe and it is encouraging that there are now increasing numbers of members from all the continents. New members are very welcome as they bring with them new ideas and innovations.

AEPC and its Working Groups aim to enhance collaboration amongst members for scientific research, promoting training, professional development and to maintain high standards of professional practice. The work on behalf of children and patients with congenital heart diseases is global and the AEPC has made itself a global organisation by its close collaboration with other international organizations. These include the European Society of Cardiology; the Japanese Society of Paediatric Cardiology and Cardiac Surgery (JSPCCS); the European Association for Cardio-Thoracic Surgery (EACTS) and; the Adult Congenital and Pediatric Cardiology Section of the American College of Cardiology (ACC); the Asia Pacific Pediatric Cardiac Society (APPCS); the European Heart Surgeons Association (ECHSA), the World Congress of Paediatric Cardiology and Cardiac Surgery and several others.

\section{Working groups}

Several activities of AEPC are organized by the Working Groups. The Working Groups represent different subspecialties and specific areas of paediatric and congenital cardiology. The Association now has 13 Working Groups, to bring together workers with similar interests in order to facilitate research and collaboration and to organise teaching and training.

\section{Annual meetings}

An Annual Meeting and an Update-On Course are organised by the AEPC, usually in the third week of May in collaboration with one of the member countries. The AEPC organizes 2-3 Teaching courses for trainees in Paediatric Cardiology each year. Additional symposia and courses are usually a part of the annual meetings. 


\section{The International Society for Nomenclature of Paediatric and Congenital Heart Disease}

$\mathrm{T}$ He International Society for Nomenclature of Paediatric and Congenital Heart Disease (ISNPCHD) is an established not-for-profit organization, incorporated in Canada, with the collective mission to identify, standardize, and maintain an international system of nomenclature, the International Paediatric and Congenital Cardiac Code (IPCCC), to enhance global communication and facilitate patient care, research, and training in paediatric and congenital heart care across disciplines. In other words, the IPCCC provides a common language and terminology, inclusive of definitions and imaging, which covers the entire field of diagnostic and procedural terms for paediatric and congenital heart care. The IPCCC is the product of the cross-mapping work by the ISNPCHD Nomenclature Working Group during the decade following the publication in 2000 of two similar and complementary nomenclature systems, namely the International Congenital Heart Surgery Nomenclature and Database Project under the auspices of the European Association for Cardio-Thoracic Surgery and Society of Thoracic Surgeons, and the European Paediatric Cardiac Code under the auspices of the Association for European Paediatric Cardiology. The IPCCC is owned by the ISNPCHD but is digitally published for free download for private use (www.ipccc. net) in these two Societal versions, both with a Long List of over 10,000 terms with qualifiers, and a Short List of up to 1000 terms for use in databases when comparing institutional outcomes, both nationally and internationally. The Long Lists of the IPCCC comprehensively cover the field of paediatric and congenital cardiac care, including diagnoses of congenital and related acquired pathology, comorbid conditions, transcatheter and operative procedures, and a full list of postprocedural complications. The Short Lists are used within databases across the world with over 500,000 registered patients. The ISNPCHD encourages the commercial use of the
IPCCC by requiring and providing free-of-charge license agreements for its use, to ensure that the IPCCC remains unaltered by parties other than the ISNPCHD.

Since 2007 the ISNPCHD has been operating through three working groups:

- The Nomenclature Working Group, which continues to maintain, develop, expand, update, and preserve the IPCCC;

- The Definitions Working Group, which is engaged in writing definitions for the terms in the IPCCC. More recently this initiative has focused on the terms provided by the ISNPCHD at the behest of the World Health Organization (WHO) for the $11^{\text {th }}$ revision of the International Classification of Diseases;

- The Archiving Working Group, which is engaged in linking images and videos to the IPCCC, including cardiac morphologic specimens, echocardiography, angiography, computerized axial tomography, magnetic resonance imaging, intraoperative photographs and intraoperative videos.

The ISNPCHD, through the IPCCC, enables institutions from around the world to seamlessly communicate with each other, comparing and then improving outcomes and the quality of care that is given to children, young people, and adults born with malformed hearts. This common language enables institutions to learn from those hospitals performing best at a global level, as well as facilitating research projects, such as comparing the longer term quality of life and complications in those who have required operative and transcatheter interventions. In addition, the nomenclature with corresponding definitions and matching imaging, enhances teaching of this specialty to the next generation of clinicians dedicated to pediatric and congenital cardiac care, both in the developed and developing world. 